\title{
A questão do aborto na democracia: descompassos e desafios
}

\author{
Aborto e Democracia \\ BIROLI, Flávia; MIGUEL, Luis Felipe (Orgs.).
}

São Paulo: Alameda, 2016, 242 p.

A temática do aborto tem sido parte do agenda dos movimentos feministas desde seu surgimento, cujo período exato pode variar conforme a análise ou o ponto de vista. Há quem postule o início do feminismo ainda no século XVIII-com Olympe de Gouges e Mary Wollstonecraft - ou no século XIX - com as sufragistas. A maior parte das/os pesquisadoras/es, contudo, remonta às décadas de 1950 e 1960, quando grupos organizados formados por mulheres ganharam maior visibilidade especialmente na Europa e nos Estados Unidos. Embora as diferentes etapas desta história apresentem demandas e pautas específicas acionadas ao sabor das conjunturas, a discussão sobre o papel das mulheres na sociedade sempre foi central. Além disso, seja reivindicando participação nas decisões políticas, seja cobrando resultados das mudanças sociais, seja lutando pelo direito ao voto ou questionando o essencialismo que destina à mulher o espaço doméstico, as questões relacionadas à maternidade sempre estiveram presentes.

Os questionamentos acerca desta função como exclusiva às mulheres e socialmente considerada como necessária, desencadearam a problemática do aborto. Prática presente em todas as etapas da História, apesar de transformações em seu significado e simbologia (Giulia GALEOTTI, 2007), atualmente possui variações de estatuto em diferentes lugares do mundo. No Brasil, a criminalização desencadeia situações complexas envolvendo a saúde pública, os direitos das mulheres, o desempenho da política, as relações de gênero, as concepções coletivas e individuais sobre o direito ao corpo e o significado da vida, em que pesam de forma expressiva a vivência das religiosidades.

Dessa forma, pesquisadoras/es de diversas áreas do conhecimento têm se debruçado sobre o tema e favorecido discussões em âmbito acadêmico sobre o aborto, as quais se estendem a universos sociais mais amplos, denotando a necessidade de um debate mais denso sobre o assunto. Dissertações de mestrado, teses de doutorado, publicações em periódicos, livros e coletâneas se avolumam e, desde a década de 1990, têm sido cada vez mais frequentes como atestam, dentre outros, os trabalhos de Fabíola Rohden (2003), Alcilene Cavalcante e Dulce Xavier (2006), Danda Prado (2007), Mônica Bara Maia (2008), Maurílio Matos (2010), Wilza Vieira Villela e Regina Maria Barbosa (2011), Gustavo Venturi e Tatau Godinho (2013).

O ambiente redemocratizado, especialmente após a Constituição de 1988, tem possibilitado maior atenção às temáticas que versam sobre os direitos das mulheres, ainda que em termos efetivos as conquistas legais tenham sido pouco expressivas, marcadas menos por avanços que por retrocessos. A despeito disso, as investidas de grupos de pesquisa, estudantes e professoras/ es de todo o Brasil avançam na direção de produzir conhecimentos que possam promover transformações sociais.

Este é o caso das/os pesquisadoras/es organizadoras/es da coletânea Aborto e Democracia, Flávia Biroli e Luis Felipe Miguel, coordenadoras/es do Grupo de Pesquisa sobre Democracia e Desigualdades (Demodê) da Universidade de Brasília (UnB). Publicado em 2016 
pela Editora Alameda, o livro resulta do trabalho desenvolvido pelas/os autoras/es, cuja produção individual e conjunta (Flávia BIROLI, 2013, 2014; Luis Felipe MIGUEL, 2000, 2014, 2015; BIROLI; MIGUEL, 2011, 2014) demonstra embasamento para tratar o tema, bem como a intensidade de sua relevância em nossa sociedade.

Aborto e Democracia é estruturado em nove capítulos, introduzidos pelas/os organizadoras/es que, desde as primeiras páginas, têm a preocupação em atentar para a diversidade das abordagens que costuram a questão do aborto como ponto de partida, sempre tendo como pano de fundo o contexto democrático e as contradições que apresenta na conjuntura brasileira e latino-americana.

O primeiro capítulo, de autoria de Flávia Biroli, "Aborto, justiça e autonomia" é resultado das pesquisas "Direito ao aborto e sentidos da maternidade: atores e posições em disputa no Brasil contemporâneo" e "Desigualdades e preferências: a tensão entre o valor da autonomia individual e a crítica à opressão na teoria política contemporânea". O texto está dividido em quatro seções e aborda a discussão sobre a autonomia das mulheres conectando-a aos paradigmas liberais que contornam o debate sobre direito ao aborto. A centralidade das elaborações feministas é acionada e complexificada a partir de suas variações, culminando com uma reflexão que relaciona o sentido da vida e sua relação entre o aborto, a noção de autonomia e de cidadania.

O texto que segue, escrito por Luis Felipe Miguel, "O direito ao aborto como questão política", tem como mote a arena formada durante as eleições presidenciais de 2010 e 2014 quando ficaram evidentes os limites do Estado laico, a despeito de sua oficialidade. É a partir da necessidade da laicidade que o autor percorre a especificidade da questão do aborto. O pape assumido pelos líderes religiosos, por sua vez, atenta para as condições desfavoráveis às mudanças no que diz respeito aos direitos das mulheres, especialmente quando relacionados a tal problemática. Este, porém, não se constituiria o único entrave às transformações que buscam ser viabilizadas. Há que se refletir, ainda, sobre a dificuldade dos movimentos que lutam pelos direitos das mulheres em manter suas agendas e ampliá-las mesmo diante dos obstáculos promovidos por grupos opositores.

O terceiro capítulo, "Do direito ao poder de ser mãe: sobre o direito ao aborto e maternidade", de Maria Aparecida Azevedo Abreu, aborda a questão a partir de um roteiro que primeiramente enquadra a prática do aborto a partir da perspectiva moral e criminal. Segue explorando a tensão entre o direito à vida do feto e o direito de escolha da mulher para, então, abordar outro nível de tensão, relativo ao direito da mulher com relação à experiência de uma maternidade indesejada e o dever de cuidado de mães e pais. Merece destaque o cuidado da autora em introduzir as relações de gênero relativas à maternidade/paternidade. Ainda que tal experiência envolva ambos como progenitores, são diversas as manifestações que excluem a responsabilidade dos homens nesta trajetória. Finalmente, o trato com o tema da maternidade encontra no texto um olhar sensível à complexidade desta experiência levantando, embora sem aprofundamento, a concepção de poder vinculada à maternidade, distanciando-a da ideia de fardo ou de punição, como situações de violência obstétrica podem fomentar.

"Política, direitos humanos e aborto: uma análise das opiniões de líderes pentecostais brasileiros", escrito por Maria das Dores Campos Machado, parte de casos emblemáticos ocorridos no ano de 2014 - quando duas mulheres morreram em decorrência da realização de abortos clandestinos, amplamente divulgados pela mídia. A autora se lança à reflexão que vislumbra as contradições entre preceitos religiosos e a efetivação dos direitos humanos, percorrendo o histórico de disputas simbólicas entre setores de religiões cristãs - tanto a católica quanto as pentecostais - e movimentos LGBTT. O crescimento e a popularidade dos pentecostais entre a população de baixa renda é inserido como ingrediente importante nos espaços conquistados oficialmente por dirigentes que fazem valer suas convicções pessoais na efetivação ou objeção de ações políticas sobre o aborto. Mais uma vez a laicidade do Estado é colocada à prova. A autora elabora sua reflexão tendo como base relatos de líderes pentecostais, - que amplia a discussão para além de formulações únicas sobre a relação entre religião e aborto. A possibilidade de observar posicionamentos mais ou menos "liberais" importa na medida em que reforça a necessidade de aprofundar abordagens que reduzem a posição das matrizes religiosas como exclusivamente contrárias ao aborto, sem levar em consideração sua pluralidade e as tendências inclusivas atuais.

O quinto capítulo, de autoria de Naara Luna, intitulado "Aborto e células-tronco embrionárias no Senado: choque de moralidades sobre a gestão da vida", tem como base discursos de parlamentares e audiências públicas realizadas 
entre 2003 e 2010 no Senado sobre a nova lei de biossegurança. A pesquisa foi feita a partir de informações disponíveis no site do Senado Federal, utilizando palavras-chave como: "aborto", "nascituro", "reprodução assistida", "fertilização in vitro" e "embrião". O materia recolhido foi organizado e analisado em duas etapas: o quadriênio de 2003-2006 e o de 20072010. Uma das constatações da autora reflete o escasso espaço para o debate sobre o aborto enquanto ampliam-se projetos que valorizam a condição de pessoa relativa ao feto e ao embriẫo. Fica evidente o embate entre discursos moralizantes sobre o sentido da vida e os desafios colocados pelos progressos científicos que podem transformar vidas.

O capítulo seguinte retoma a parceria de Biroli e Miguel, desta vez acrescida pela experiência de Rayani Mariano. "O debate sobre o aborto na Câmara dos Deputados, de 1990 a 2014" mantém o escopo da investigação no âmbito político oficial, também amparado nas pesquisas desenvolvidas pelas/os autoras/es em suas atividades docentes e de pesquisa, em que se somam estudantes que contribuem no andamento dos estudos, demonstrando os tentáculos construídos em ambientes acadêmicos. Somente esta condição permitiria a análise da totalidade dos discursos sobre a questão do aborto pronunciados em plenário ao longo de 24 anos. Para apresentar o debate na Câmara dos Deputados. as/os autoras/es lançam mão de gráficos que auxiliam na sistematização de tamanho número de dados coletados, bem como na organização dos argumentos observados. $O$ resultado apresentado pelas/os autoras/es remete ao fechamento do debate em função da prevalência de discursos morais e religiosos, conduzindo à redução da possibilidade de se vislumbrar o aborto como questão de cidadania. Como solução, apontam para a intensificação da pressão que extrapola o contexto parlamentar tendo em vista as possibilidades de ser um ambiente social menos desfavorável às restrições atuais.

Novamente Maria Aparecida Azevedo Abreu se faz presente na obra com "Aborto $e$ maternidade no STF: análise dos julgamentos da ADI 3510 e da DPF 54". Se no capítulo anterior de sua autoria Abreu se baseia em questões que transitam pelas relações de gênero, neste sua atenção se volta para fontes provenientes de ações legais que tiveram espaço no STF (Supremo Tribunal Federal): a ADPF (Ação de Descumprimento de Preceito Fundamental) número 54, que diz respeito à legalização do aborto para casos de anencefalia; e a ADI (Ação
Direta de Inconstitucionalidade) número 3510 , que discorre sobre a autorização de pesquisas científicas com células-tronco embrionárias. A autora busca os pontos convergentes entre as ações observadas, abordando em ambas a maneira como são consideradas a definição de vida e direito à vida, as concepções de gravidez e maternidade, culminando com a discussão sobre o aborto e o direito ao mesmo. A despeito das especificidades de cada caso, a autora aponta para a ausência de preocupação em conferir espaço de atuação para as mulheres, o que as afastaria da discussão e decisão sobre permissivos a respeito da prática do aborto.

O penúltimo capítulo, "O aborto e as eleições de 2010: o papel do jornalismo na definição dos discursos conservadores", de Denise Mantovani, analisa o contexto da disputa eleitoral de 2010 a partir das matérias noticiadas pelos jornais $O$ Globo, Folha de S. Paulo e O Estado de S. Paulo. A autora parte da função social da imprensa como componente da construção da realidade e da opinião dos sujeitos para desvelar como esta ałuação desencadeou desdobramentos nas pesquisas eleitorais na ocasião e, provavelmente, nos seus resultados efetivos. Oferecendo dados sistematicamente analisados, é possível identificar desde os elementos que regem a agenda jornalística remetendo à impossibilidade de imparcialidade - até seus efeitos sobre aqueles que consomem - material produzido. O aborto como tema primordial no período estudado é o mote para o desencadeamento de mudanças expressivas no andamento da disputa eleitoral. A exposição de Mantovani destaca a discrepância entre as possíveis opiniões pessoais e mesmo de grupos de jornalistas que podem ser favoráveis ao direito ao aborto e as necessidades objetivas e mercadológicas organizadas pelo momento em questão, em que são privilegiados resultados na luta pelo poder político em detrimento da agenda que discute os direitos das mulheres e seus avanços.

A publicação é finalizada com a contribuição de Susana Rostagnol: "As vicissitudes da lei da interrupção voluntária da gravidez no Uruguai: estratégias conservadoras para evitar o exercício do direito de decidir das mulheres". Em um primeiro momento, o texto pode parecer fugir aos encaminhamentos da obra que versam até aqui sobre o contexto brasileiro. $O$ pano de fundo uruguaio, contudo, atenta para a universalidade da questão. Mais que isso, problematiza o tema desconstruindo a visão que simplifica a descri- 
minalização do aborto em ambientes marcados pela redemocratização. Ao descortinar o contexto da recente descriminalização do aborto no país, oferece elementos que apontam para as dificuldades de implementação da lei que esbarra em pressupostos morais e éticos de longa duração. As relações de poder entre o corpo médico e as mulheres que necessitam do procedimento atestam elementos que ultrapassam a legislação e lançam desafios para a concretização do direito à autonomia do corpo feminino.

É possível observar a preocupação das/os organizadoras/es em estabelecer uma linha temática que percorre especialmente as duas últimas décadas. Os três primeiros capítulos versam sobre aspectos relacionados ao direito. Primeiramente, como questão que envolve a aplicação da justiça em contraste com o direito à autonomia; em seguida, se volta para elementos de ordem política para, então, refletir sobre a maternidade como um direito que pode ser ou não desejado ou possível.

O quarto e o quinto capítulos introduzem discursos oficiais que se ocupam de temas fundamentais quando se trata do aborto: a religiosidade e os avanços na área da saúde, apontando para elementos da moral e da ética diante de diferentes situações. Os capítulos seis e sete dão continuidade à abordagem explorando fontes produzidas no âmbito político da Câmara dos Deputados, do Senado e do Supremo Tribunal Federal.

Ainda no espectro dos discursos produzidos em diferentes instâncias da sociedade, temos o texto que trata dos impactos do jornalismo nas decisões pessoais e políticas, alertando para a responsabilidade destes meios de comunicação na formação da opinião pública. A finalização da obra, por sua vez, evoca a realidade uruguaia. Em muitos casos, imediatamente tida como modelo, é complexificada mostrando a necessidade de aprofundar as análises comparativas, sugerindo a importância de avaliar cada caso em suas particularidades.

A coletânea atenta, assim, para múltiplos olhares sobre o aborto na contemporaneidade. sobretudo, na sociedade brasileira. A democracia em construção - característica do contexto analisado - é o ponto central para proceder às investigações que fazem parte do trabalho, enfatizando os paradoxos vivenciados tanto em âmbito oficial e público quanto em universos particulares. Isso permite perceber o quanto são partes de um todo e denota as responsabilidades envolvidas para aqueles que se dedicam aos estudos sobre o aborto.
Trata-se de uma obra que contribui para os trabalhos sobre o tema e sinaliza o amadurecimento dos estudos das/os autoras/es e seu comprometimento com a produção de conhecimentos sobre a questão. Ainda que seja notável o posicionamento pessoal das/os responsáveis pela publicação, o rigor dos estudos que servem de base para as reflexões imprime ao livro seu valor científico e concatenado com a observância de métodos e teorias a partir dos quais podemos avançar nas discussões sobre o aborto.

A leitura de Aborto e Democracia é indispensável aos que estudam a temática do aborto, mas não somente. Possibilita aprofundar sobre assuntos como a democracia, a política, os impactos da imprensa na elaboração das opiniões, as relações de gênero e as religiosidades.

Mas, como em todo projeto, sempre há lacunas... Apesar de centralidade das mulheres diante do assunto, poucas vezes suas vozes ecoam. Tal ausência não configura, no entanto, falta de preocupação das/os envolvidas/os. Provavelmente, estimule novas investidas que encontram nesta obra excelente oportunidade de avançar nas discussões sobre o aborto na contemporaneidade.

\section{Referências}

BIROLI, Flávia. Autonomia e desigualdades de gênero: contribuições do feminismo para a crítica democrática. Niterói: Eduff, 2013. . Família: novos conceitos. São Paulo: Editora Fundação Perseu Abramo, 2014.

BIROLI, Flávia; MIGUEL, Luis Felipe (Orgs.). Aborto e Democracia. São Paulo: Alameda, 2016.

BIROLI, Flávia; MIGUEL, Luis Felipe. Caleidoscópio convexo: mulheres, política e mídia. São Paulo: Editora Unesp, 2011.

BIROLI, Flávia; MIGUEL, Luis Felipe. Feminismo e política: uma introdução. São Paulo: Boitempo, 2014.

CAVALCANTE, Alcilene; XAVIER, Dulce (Orgs.). Em defesa da vida: aborto e direitos humanos. São Paulo: Católicas pelo Direito de Decidir, 2006.

GALEOTTI, Giulia. História do Aborto. Coimbra: Edições 70, 2007

MAIA, Mônica Bara (Org.). Direito de decidir: múltiplos olhares sobre o aborto. Belo Horizonte: Editora Autêntica, 2008.

MATOS, Maurílio Castro de. A Criminalização do aborto em questão. São Paulo: Almedina, 2010.

MIGUEL, Luis Felipe. Mito e discurso político. Campinas: Editora Unicamp, 2000. 
Democracia e representação: territórios de disputa. São Paulo: Editora Unesp, 2014

O nascimento da política moderna: de Maquiavel a Hobbes. Brasília: Editora UnB, 2015.

PRADO, Danda. O que é aborto. São Paulo: Brasiliense, 2007.

ROHDEN, Fabíola. A arte de enganar a natureza. Contracepção, aborto e infanticídio no início do século $X X$. Rio de Janeiro: Editora FIOCRUZ, 2003.

VILLELA, Wilza Vieira; BARBOSA, Regina Maria. Aborto, saúde e cidadania. São Paulo: Editora Unesp, 2011.

VENTURI, Gustavo; GODINHO, Tatau. (Orgs.). Mulheres brasileiras e Gênero nos Espaços Público e Privado: uma década de mudanças na opinião pública. São Paulo: Editora Fundação Perseu Abramo: Edições Sesc SP, 2013.
[Recebida em 30/12/2016

e aprovada em 07/02/2017

Marcela Boni Evangelista

Universidade de São Paulo, São Paulo, Brasil

Marcela Boni Evangelista (marcela.boni @gmail.com) é doutora em História Social pela Universidade de São Paulo (FFLCH-USP). No mesmo Departamento realizou pesquisa de mestrado (2011) intitulada "Padecer no paraíso? Experiências de mães de jovens em conflito com a lei?", recentemente publicada em livro e e-book pela Editora Pontocom. É pesquisadora do Núcleo de Estudos de História Oral (NEHO-USP) e do Grupo de Pesquisa em Gênero e História da USP (GRUPEG-HIST). Integra a equipe editorial da "Oralidades - Revista de História Oral". Entre os anos de 2001 e 2008 integrou a equipe do Núcleo de Estudos da Violência (NEV-USP). 